\title{
As descobertas genômicas do SARS-CoV-2 e suas implicações na pandemia de COVID-19
}

\section{The genomic discoveries of SARS-CoV-2 and their implications for the COVID-19 pandemic}

\author{
Luana Nepomuceno Gondim Costa Lima ${ }^{1,2,3}$ [D , Maisa Silva de Sousa ${ }^{4}$ [ , Karla Valéria Batista Lima ${ }^{1,2,3}$ (C)
}

1. Seção de Bacteriologia e Micologia do Instituto Evandro Chagas (IEC), Ananindeua, PA, Brasil. 2. Docente do Programa de Pós-Graduação em Epidemiologia e Vigilância em Saúde (IEC), Ananindeua, PA, Brasil. 3.Docente do Programa de Pós-Graduação em Biologia Parasitária na Amazônia da Universidade do Estado do Pará (UEPA), Ananindeua, PA, Brasi, 4. Docente do Programa de Pós-Graduação em Doenças Tropicais, Núcleo de Medicina Tropical da Universidade Federal do Pará (UFPA), Belém, PA.

\section{Resumo}

Objetivo: Auxiliar no entendimento da COVID-19 em relação à origem do SARS-CoV-2, suas descobertas genômicas, patogenia, possíveis hospedeiros primários e intermediários, além da comparação com outros coronavírus. Metodos: foram utilizadas as bases de dados Scientific Eletronic Library Online e PubMed, com artigos de revisão e originais, em língua portuguesa e inglesa, pesquisados no período de 05 de março a 10 de abril de 2020 , adotando os seguintes descritores: SARS-CoV, COVID-19, coronavirus, Wuhan, genome, structure, origin, transmission, evolution, zoonotic. Os artigos originais identificados foram incluídos nesta revisão, juntamente com artigos de suporte referenciados por estes. Resultados: As características genômicas descritas até o momento podem explicar, em parte, a infectividade e a transmissibilidade do SARS-CoV-2 em humanos. Devido aos notáveis recursos de SARS-CoV-2, incluindo o local otimizado do domínio de ligação ao receptor (RBD) e de clivagem polibásica, é pouco provável um cenário laboratorial para a origem do SARS-CoV-2. Conclusão: Para o presente, é de extrema importância obter mais dados genéticos e funcionais sobre o SARS-CoV-2, incluindo estudos em animais, sequenciamento do vírus em casos muito precoces e identificação dos parentes virais mais próximos do SARS-CoV-2 que circulam em animais.

Palavras-chave: Coronavirus. Pandemia. Patogenicidade. Transmissão.

\section{Abstract}

Objective: tTo assist in the understanding of COVID-19 in relation to the origin of SARS-CoV-2, its genomic discoveries, pathogenesis, possible primary and intermediate hosts, in addition to comparison with other coronaviruses. Methods: the Scientific Electronic Library Online and PubMed databases were used, with review articles and originals, in Portuguese and English, researched from March 5 to April 10, 2020, adopting the following descriptors: SARS-CoV , COVID-19, coronavirus, Wuhan, genome, structure, origin, transmission, evolution, zoonotic. The original articles identified were included in this review, along with supporting articles referenced by them. Results: The genomic characteristics described so far may partly explain the infectivity and transmissibility of SARS-CoV-2 in humans. Due to the remarkable resources of SARS-CoV-2, including the optimized site of the receptor binding domain (RBD) and polybasic cleavage, a laboratory scenario for the origin of SARS-CoV-2 is unlikely. Conclusion: For the present, it is extremely important to obtain more genetic and functional data on SARS-CoV-2, including studies on animals, sequencing of the virus in very early cases and identification of the closest viral relatives of SARS-CoV-2 that circulate in animals.

Keywords: Coronavirus. Pandemics. Pathogenicity.Transmission.

\section{INTRODUÇÃO}

Os coronavirus (CoVs) são, tradicionalmente, considerados patógenos não letais para seres humanos, causando, aproximadamente, $15 \%$ dos resfriados comuns. Até o ano de 2019, seis diferentes espécies de CoV serão conhecidas como causa de doença em seres humanos; entre as quais, quatro delas, 229E, NL63, OC43, e o HKU1, de alta prevalência e associados a quadros de resfriados e infecções leves do trato respiratório superior em pacientes imunocompetentes de todas as faixas etárias. As outras duas espécies, severe acute respiratory syndrome coronavirus (SARS-CoV) e a Middle East respiratory syndrome coronavirus (MERS-CoV) têm origem zoonótica e estão associadas a quadros graves e, potencialmente, fatais de insuficiência respiratória. O SARS-CoV foi responsável por um surto originalmente na China em 2003 com 8.096 casos em 29 países e 774 mortes (letalidade de 9,5\%); enquanto o MERSCoV foi o agente responsável pelo surto ocorrido no Oriente Médio, originalmente na Arábia Saudita, no ano de 2012, com registro de 2.494 casos em 27 países e 858 mortes (letalidade de $34 \%)^{1,2}$.

Em 2019, foi encontrado um CoV humano mais infectivo do que o SARS-CoV e MERS-CoV, um novo coronavirus zoonótico, que cruzou espécies para infectar humanos. Esse vírus, chamado provisoriamente de 2019-nCoV, foi identificado pela primeira 
vez em Wuhan, na província de Hubei, China, em pessoas de um mercado de frutos do mar e de animais vivos ${ }^{3}$. Devido ao fato de o 2019-nCoV ser altamente homólogo ao SARS-CoV, foi nomeado SARS-CoV-2 pela Organização Mundial da Saúde (OMS) em 11 de fevereiro de 2020, e a doença associada foi denominada CoV Doença-19 (COVID-19) ${ }^{4,5}$. Portanto, o SARSCoV-2 é responsável pelo terceiro surto de CoV na história da humanidade.

Casos de pneumonia com origens desconhecidas foram relatados, pela primeira vez, em Wuhan, em 31 de dezembro de 2019 pela Comissão National de saúde da China ${ }^{6}$. Em 12 de janeiro de 2020, foram isolados em Wuhan cinco genomas de SARS-CoV-2 e, em 15 de janeiro de 2020, o primeiro caso fatal de Wuhan foi relatado ${ }^{5-7}$; enquanto isso, a epidemia espalhouse, rapidamente, para as cidades vizinhas e outros países. Em 20 de janeiro, foi relatada a infecção de profissionais da saúde, confirmando a transmissão entre humanos ${ }^{8}$, e, no dia 24 de janeiro, o primeiro estudo clínico sobre a doença relatou que, dos 41 pacientes com casos confirmados, 21 tiveram contato com o mercado de frutos do mar de Wuhan ${ }^{6}$. No dia 30 de janeiro, a OMS declarou o surto de SARS-CoV-2 como uma emergência de saúde global, estando a doença espalhada em toda a China e em 50 outros países ${ }^{5}$

Em 30 de janeiro de 2020, eram conhecidos 42 genomas, e uma análise filogenética dessas amostras revelou estarem relacionadas até sete mutações com um ancestral comum, indicando que a primeira infecção em seres humanos ocorreu em novembro ou dezembro de $2019^{5,7,9}$. Em 13 de março de 2020, estavam já disponíveis publicamente 410 genomas de SARS-CoV- $2^{9}$.

Em 20 de março de 2020, foi declarado que a transmissão do novo coronavírus passou a ser considerada comunitária em todo o território brasileiro. Em 26 de abril de 2020, o Brasil era o 2o país das Américas em número de infectados (60.888) e o 12 o em número de óbitos (3.670) Na mesma data, já eram notificados 2.804 .796 casos de infectados com 193.710 óbitos no mundo, estando os Estados Unidos da América com o maior número de casos $(899.281)^{10}$.

Em 20 de março de 2020, foi declarado que a transmissão do novo coronavírus passou a ser considerada comunitária em todo o território brasileiro. Em 26 de abril de 2020, o Brasil era o 2o país das Américas em número de infectados (61.888) e em número de óbitos $(3.670)^{10}$. Na mesma data já eram notificados 2.804.796 casos de infectados com 193.710 óbitos no mundo, estando os Estados Unidos da América com o maior número de casos (899.281).

Em meio à emergência global de saúde pública da COVID-19, é importante entender as origens da pandemia, pois a compreensão detalhada de como um vírus animal ultrapassou os limites das espécies para infectar seres humanos de maneira tão produtiva ajudará na prevenção de futuros eventos zoonóticos, na busca de alvos para drogas e de marcadores laboratoriais para auxiliar no diagnóstico e prognóstico da doença. Assim, em função da relevância da situação epidemiológica da COVID-19, esta revisão resume o progresso das pesquisas com análises genômicas em relação à origem do SARS-CoV-2, patogenia, assim como seus possíveis hospedeiros primários e intermediários, comparando, também, o SARS-CoV-2 com o SARS-COV e o MERS-CoV.

\section{MÉTODOS}

A pesquisa bibliográfica foi realizada por meio de consulta à base de dados Scientific Eletronic Library Online (SciELO) e PubMed. Após a análise do título, resumo e textos completos, foram utilizados artigos de revisão e originais, em língua portuguesa e inglesa, pesquisados no período de 05 de março a 10 de abril de 2020. Utilizaram-se os seguintes descritores: SARSCoV, COVID-19, coronavirus, Wuhan, genome, structure, origin, transmission, evolution, zoonotic e todas as combinações de associação entre elas. Os artigos originais identificados foram incluídos nesta revisão, juntamente com artigos de suporte referenciados por estes.

\section{Características do SARS-CoV-2}

Os coronavírus foram descritos, pela primeira vez, em 1966 por Tyrell e Bynoe, que cultivavam os vírus de pacientes com resfriados comuns ${ }^{11}$. São uma subfamília de grandes e envelopados vírus contendo morfologia esférica, com cerca de 100 a 160 nm de diâmetro.Visualizados na microscopia eletrônica como círculos com espículas que se exteriorizam de sua superfície, formando projeções semelhantes a uma coroa solar (a palavra "corona", em latim, tem o significado de coroa). Eles podem ser divididos nos gêneros alfa, beta, gama e delta coronavírus, dos quais os CoVs alfa e beta infectam humanos. Os beta-coronavírus podem causar doenças graves e fatais, enquanto os alfa-coronavírus causam infecções assintomáticas ou levemente sintomáticas. Os alfa e beta-coronavírus são, aparentemente, originários de mamíferos, em particular de morcegos, enquanto o vírus gama e delta são originários de porcos e pássaros ${ }^{4}$.

O arranjo de genes no genoma do SARS-CoV-2 é: 5'UTRreplicase (orf1ab)-Spike (S)- orf3a-Envelope (E)- Membrane (M)- orf6- orf7a- orf8-Nucleocapsid (N)- orf10- 3'UTR. As principais diferenças entre o SARS-CoV-2 e o SARS-CoV são nos genes Spike, orf3a e orf8, que são conhecidos por codificar indutores da ativação do inflamassoma de receptores tipo NOD 3 (NLRP3) e por codificar uma proteína que inibe a expressão de interferon $\beta$ (IFN $\beta$ ). O SARS-CoV-2 forma novas proteínas mais curtas e é codificado pelo gene orf3a e por orf8. Assim, surge a hipótese de que o SARS-CoV-2 pode ser menos eficiente na supressão da resposta antiviral e na ativação do inflamassoma de NLRP3 do que o SARS-CoV, porém isso deve ser testado.

O genoma dos CoVs alberga um RNA de fita simples, polaridade positiva e com tamanho variando entre $26 \mathrm{~kb}$ e $32 \mathrm{~kb}$. Apresentam quatro proteínas estruturais, conhecidas 
como proteínas S (spike), E (envelope), M (membrana) e $\mathrm{N}$ (nucleocapsídeo). As infecções por vírus iniciam com a ligação de partículas virais aos receptores de superfície celulares. 0 reconhecimento de receptores é, portanto, um determinante importante do tropismo de células e tecidos de um vírus. permite ao vírus ligar-se à membrana de uma célula hospedeira (figura 1). Os receptores celulares são a enzima conversora de angiotensina 2 (ACE2) para o SARS-CoV e a dipeptidil peptidase 4 (DPP4) para o MERS-CoV, ocorrendo, assim, a fusão com a membrana da célula do hospedeiro ${ }^{12}$.

A proteína S, constituída por espículas de glicoproteínas,

Figura 1. Estrutura do SARS-CoV-2 e mecanismos de entrada na célula.

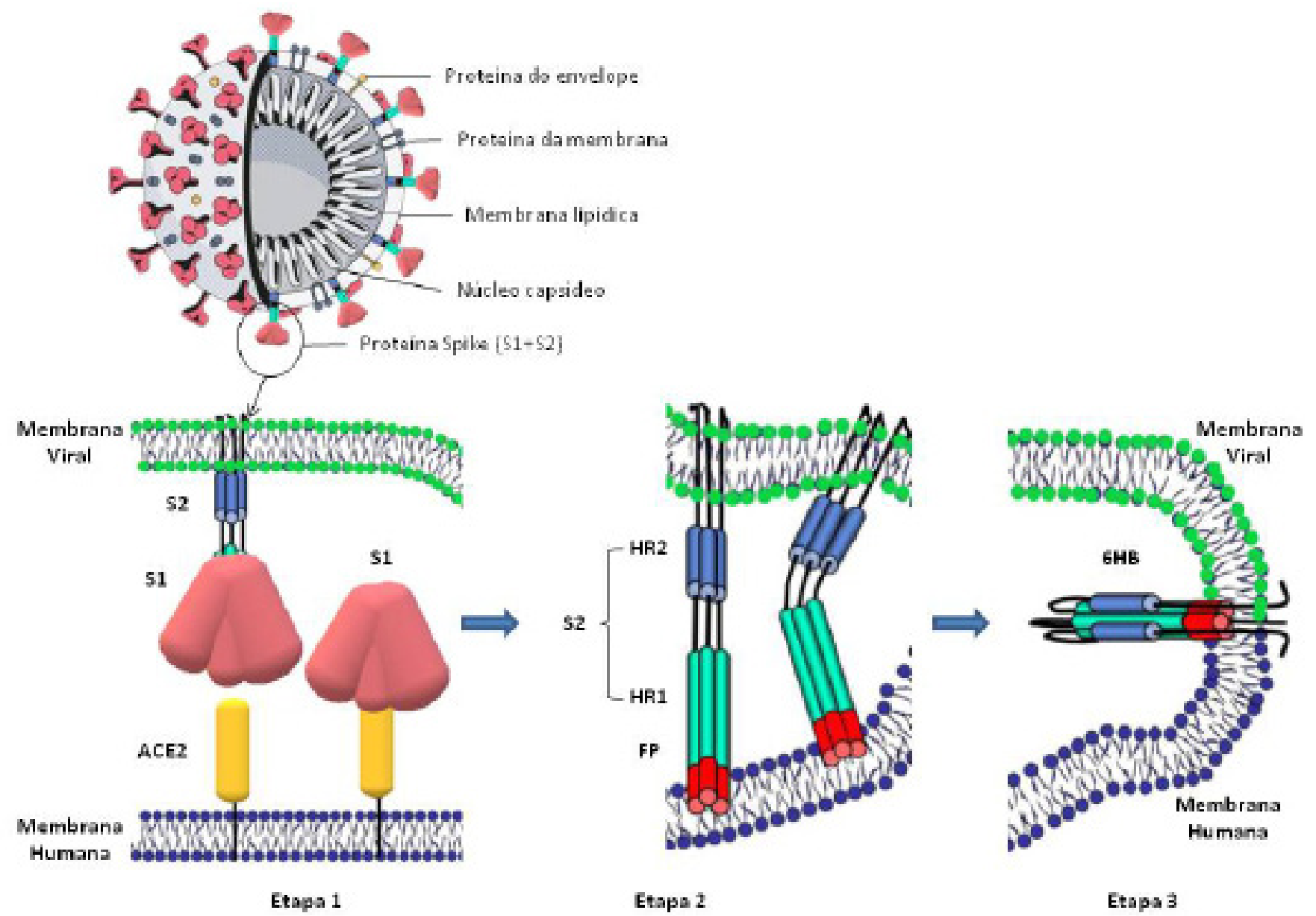

Na parte superior esquerda, desenho esquemático do vírus SARS-CoV-2, evidenciando as quatro proteínas estruturais do envelope, membrana, núcleo capsídeo e Spike (S1+S2) e membrana lipídica. A Etapa 1 ilustra a interação da proteína Spike (S1) com o receptor celular ACE2. Nesta etapa, proteases da célula alvo ativam a proteína S, clivando-a em subunidades S1 e S2. S2 muda sua conformação (etapa 2) incluindo a inserção de FP na membrana da célula-alvo e exposição do domínio HR1. A interação entre os domínios de HR2 e HR1 formam feixes de seis hélices (6-HB), trazendo o envelope viral e a membrana celular em estreita proximidade para a fusão e entrada viral (etapa 3).

Após o surto de COVID-19, os cientistas chineses determinaram, prontamente, que o SARS-CoV-2 também utiliza a ACE2 para a entrada nas células ${ }^{13,14}$. O papel fisiológico primário da ACE2 é facilitar a maturação de angiotensina, um hormônio peptídico que controla a vasoconstrição e a pressão sanguínea. A ACE2 é uma proteína de membrana tipo I expressa no pulmão, coração, rim e intestino ${ }^{15,16}$.

O SARS-CoV-2 pode invadir a célula hospedeira por endossomos ou por fusão da membrana plasmática. Em ambos os modos, a proteína S do SARS-CoV-2 medeia a ligação à membrana da célula hospedeira através da ACE2. No primeiro caso, quando os vírus são absorvidos pelos endossomos, a catepsina $L$ ativa a proteína S no endossomo; enquanto, na fusão com a membrana, a proteína $S$ é ativada por proteases celulares na proximidade do receptor ACE2. A entrada por fusão com a membrana plasmática tem menor probabilidade de desencadear imunidade antiviral das células hospedeiras e, portanto, é mais eficiente para a replicação viral| ${ }^{17-19}$.

Análise de bioinformática demonstrou que a proteína $S$ de SARS-CoV-2 exibe características semelhantes às das proteínas S de outros CoVs, incluindo uma região S1 NTD, S1 CTD, S2, uma região transmembranar e um pequeno domínio 
citoplasmático ${ }^{17}$. A proteína S trimétrica do SARS-CoV-2 é clivada em S1 e S2 pelas proteases das células hospedeiras durante a infecção, na qual a subunidade S1 é responsável pela ligação ao receptor celular e a subunidade S2 é envolvida na entrada viral.

A subunidade S1 é composta pelo peptídeo sinal (SP), domínio $\mathrm{N}$-terminal (NTD) que reconhece um receptor de superfície celular e um domínio C-terminal (CTD) que impulsiona a fusão do envelope viral com a membrana celular, os quais podem funcionar como uma entidade de ligação ao receptor também chamado domínio de ligação ao receptor (RBD). A subunidade S2 é composta pelo peptídeo de fusão (FP), um segundo sítio proteolítico (S2'), um peptídeo de fusão interno (IFP), domínio heptad repeat 1 (HR1), domínio heptad repeat 2 (HR2), domínio transmembranar (TM) e domínio fusão citoplasmático (CP)(2022) (figura 2).
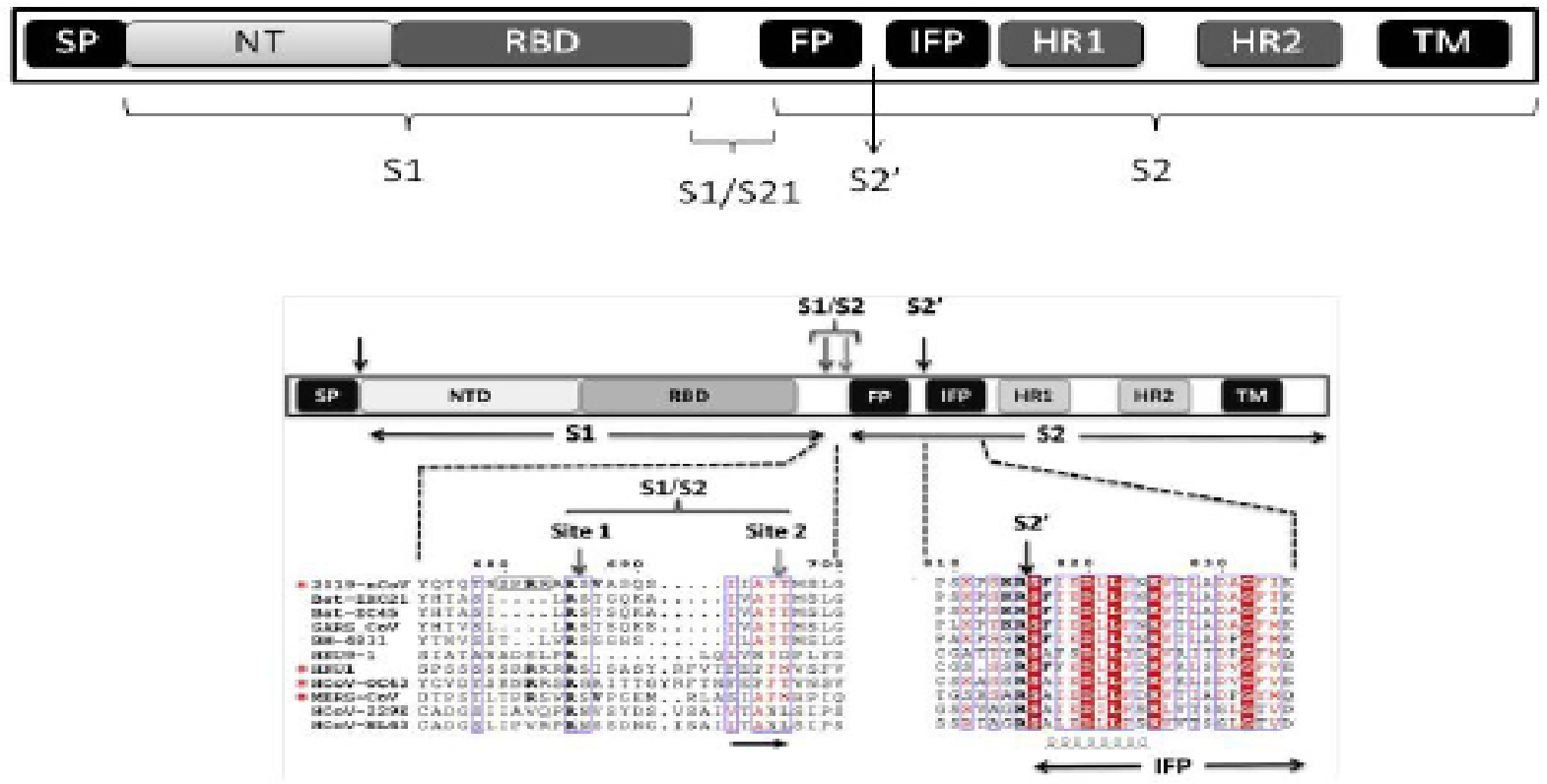

Estão destacados [] os sítios de clivagem envolvidos no processo de ligação e fusão dos vírus nas células hospedeiras. A proteína $S$ de SARSCoV-2 contém uma sequência de reconhecimento da furina "PRRARSV", semelhante ao MERS-CoV "PRSVRSV". Por outro lado, a parte "PRRA" da sequência alvo da furina no local S1 / S2 está ausente na proteína S de todos os outros SARS / SARSr-CoVs. Somente o SARS-CoV-2 contém um potencial local de clivagem para proteases de furina. Essa característica indica que o SARS-CoV-2 humano pode ganhar um mecanismo distinto para promover sua entrada nas células hospedeiras. Todas as sequências SARS-CoV-2-Wuhan-Hu-1 (QHD43416.1), Bat-CoV-RaTG13 (QHR63300.2), PCoV GX-P4L (PQIA48614.1), SARS-CoV (P59594.1), MERS-CoV (YP_009047204.1), HCoV-NL63 (YP_003767.1), HCoV-229E (NP_073551.1), HCoVOC43 (YP_009555241.1), HCoV-HKU1 (YP_173238.1) estão disponíveis no NCBI.

A proteína $S$ de SARS-CoV-2 contém uma sequência de reconhecimento da furina (PRRARSV), semelhante ao MERS-CoV (PRSVRSV) $(16,17)$. Por outro lado, a parte "PRRA" da sequência alvo da furina no local S1 / S2 está ausente na proteína S de todos os outros SARS / SARSr-CoVs (figura2). Somente o SARSCoV-2 contém um potencial local de clivagem para proteases de furina. Essa característica indica que o SARS-CoV-2 humano pode ganhar um mecanismo distinto para promover sua entrada nas células hospedeiras ${ }^{18}$.

O RBD na subunidade S1 da proteína S é a parte mais variável do genoma entre os SARS-CoV-2 e o SARS-CoV. Seis aminoácidos do RBD são críticos para a ligação à ACE2 e para determinar quais os hospedeiros do SARS-CoV. Com coordenadas baseadas no SARS-CoV, são Y442, L472, N479, D480, T487 e Y4911, que correspondem a L455, F486, Q493, S494, N501 e Y505 em SARSCoV-2. Cinco desses seis resíduos diferem entre o SARS-CoV e o SARSCoV-2, o qual tem um RBD que se liga com alta afinidade a ACE2 de humanos, furões, gatos e outras espécies com alta homologia de receptores $(20,23)$. Estudos reportaram que a proteína S do SARS-CoV-2 se liga ao ACE2 com afinidade de $\sim 15 \mathrm{nM}$, que é uma afinidade aproximadamente 10 a 20 vezes maior do que a ligação do ACE2 ao SARS-CoV 20,24,25.

\section{Interação com o hospedeiro}

Na maioria dos pacientes com COVID-19, foi relatado que, nos exames hematológicos e bioquímicos, ocorre a adiminuição da hemoglobina e o aumento dos valores de velocidade de hemossedimentação (VHS), índice de ferritina sérica, proteína C reativa, albumina e lactato desidrogenase ${ }^{26-28}$ (quadro 1).Isso implica que, com a hemoglobina diminuindo e o heme aumentando, o corpo acumula íons de ferro, causando inflamação e aumento da proteína C-reativa e albumina. Então, as células reagem ao estresse devido à inflamação, produzindo grandes quantidades de ferritina sérica para se ligarem aos íons de ferro livres para reduzir os danos. A hemoglobina consiste em quatro subunidades, $2-\alpha$ e2- $\beta$, e cada subunidade possui um heme ligado ao ferro. $O$ heme é um componente importante da hemoglobina, composto por um anel porfirínico 
no qual se acomoda em seu centro um átomo de ferro ligado a quatro átomos de nitrogênio. A estrutura do heme sem o ferro é chamada de porfirina. Quando o ferro é divalente, a hemoglobina libera dióxido de carbono e captura átomos de oxigênio nas células alveolares, oxidando o ferro atrivalente. Quando a hemoglobina é disponibilizada para outras células do corpo através do sangue, libera átomos de oxigênio e captura dióxido de carbono, reduzindo o ferro adivalente ${ }^{27,28}$.

Quadro 1. Alterações laboratoriais em pacientes com progressão desfavorável da COVID-19.

\begin{tabular}{|ll|}
\hline Albumina & Diminuição \\
Hemoglobina & Diminuição \\
Linfócitos & Diminuição \\
Alanina aminotransferase (ALT) & Aumento \\
Aspartato aminotransferase (AST) & Aumento \\
Bilirrubina total & Aumento \\
Creatinina & Aumento \\
D-dímero & Aumento \\
Ferritina & Aumento \\
Lactato desidrogenase (LDH) & Aumento \\
Procalcitonina & Aumento \\
Proteína C reativa (PCR) & Aumento \\
Tempo de protrombina (PT) & Aumento \\
Troponina cardíaca & Aumento \\
\hline
\end{tabular}

Um estudo utilizando análises de domínios conservados (MEME Suite), modelagem de homologia (swiss-model) e acoplamento molecular (Molecular docking) analisou funções de determinadas proteínas do SARS-CoV-2. Os pesquisadores demonstraram que as orf1ab, orf10 e orf3a do SARS-CoV-2 atacam o heme da cadeia 1-beta da hemoglobina, dissociando o ferro e formando a porfirina e, então, a orf8 e glicoproteínas de superfícies se combinam com a porfirina para formar um complexo, inibindo, assim, a via metabólica normal do heme e fazendo que as pessoas apresentem dispineia como um dos sintomas da COVID-19. Assim, a pneumonia por SARSCoV-2 poderia estar intimamente relacionada ao metabolismo anormal da hemoglobina em humanos ${ }^{29}$.

Um vírus poderia estar ligado à porfirina independentemente de uma célula, devido ao fato de a porfirina ter uma característica de transferência de energia por ressonância de fluorescência, na qual um doador, em um estado, excitado transfere energia para um receptor no estado fundamental através de um efeito dipolo de longo alcance. Assim, os vírus que se ligam a porfirinas poderiam obter energia através desse método induzido pela luz. Os resultados do estudo de Wenzhong et al. (2020) sugerem que o novo coronavírus poderia ser dependente da porfirina e pode ter evoluído ao longo de inúmeras gerações em um hospedeiro original como o morcego ${ }^{29}$.

A evolução do novo coronavírus também apresenta algumas características paradoxais. O SARSCoV-2 é altamente contagioso, portanto, a sua proteína S e a ACE2 humana deveriam ter uma forte capacidade de ligação. De fato, estudos reportaram à alta afinidade da ligação entre a proteína $S$ do SARS-CoV-2 e a $\operatorname{ACE} 2(20,24,25)$. No entanto, outros estudos mostraram que, apesar do SARS-CoV-2 ligar-se à ACE2 humana com alta afinidade, a interação não é ideal, e a sequência RBD é diferente daquelas demonstradas no SARS-CoV como ideal para a ligação ao receptor, tornando mais fraca a ligação do SARS-CoV-2 à ACE2 $(13,15,16,25)$. Assim, em adição ao método de ligação Spike-ACE2, supõe-se existir outro mecanismo de ligação entre o SARS-CoV-2 e a membrana do hospedeiro ${ }^{16,23}$.

Um estudo de Wenzhong et al. (2020) mostrou que a glicoproteína E2 e a proteína do Envelope do SARS-CoV-2 ligam-se, eficazmente, às porfirinas.A porfirina é um composto da classe de polímeros que contêm nitrogênio com uma forte capacidade de penetração nas membranas celulares. Portanto, em adição ao método invasivo Spike-ACE2, de alta afinidade, mas baixa força interativa, o SARS-CoV-2 também pode penetrar a membrana celular humana através de sua ligação à porfirina(29).Esse achado se apresenta como uma solução para aumentar o seu potencial de infectividade, que, provavelmente, é resultado da seleção natural em seres humanos; sendo isso, também, uma evidência de que oSARS-CoV-2, presumivelmente, não é produto de manipulação laboratorial ${ }^{29}$.

Assim como já foi demonstrado para SARS-CoV, MERS-CoV e outros CoVs humanos ${ }^{30}$, no SARS-CoV-2, no estado inativo, a subunidade S1 bloqueia os domínios FP, HR1 e HR2 na subunidade S2. Enquanto, no estado ativo (de ligação ao ACE2), após a ligação do RBD do S1 no ACE2, as proteases das células alvo ativam a proteína S, clivando-a em subunidades S1 e S2. S2 muda de conformação, incluindo a inserção de FP na membrana da célula alvo e exposição do domínio HR1. A interação entre os domínios de HR2 e HR1 formam feixes de seis hélices (6-HB), trazendo o envelope viral e a membrana celular em estreita proximidade para a fusão e entrada viral (figura 1).

O SARS-CoV-2 mostrou uma capacidade superior de fusão com a membrana plasmática do hospedeiro em comparação com o SARS-CoV. Xia et al.(2020) demonstraram que várias mutações no domínio HR1 do SARS-CoV-2 podem estar associadas às interações aprimoradas com o domínio HR2 ${ }^{31}$.

No estado de pré-fusão, os peptídeos derivados dos domínios de HR2 e HR1, designados HR2P e HR1P, interagem com os domínios de HR1 e HR2 expostos, respectivamente, e inibem a conformação $6-\mathrm{HB}$, bloqueando a fusão vira ${ }^{32}$.Um estudo demonstrou que a HR2P do SARS-CoV-2 exibiu potente atividade inibidora da fusão viral com metade da concentração inibitória

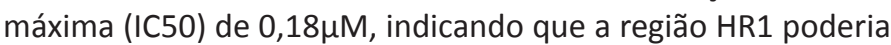
servir como um alvo para futuras drogas. Por outro lado, a HR1P do SARS-CoV-2 não exibiu efeito inibitório significativo em concentrações de até $40 \mu \mathrm{M}^{32}$.

No SARS-CoV-2, as proteases que clivam e ativam a proteína $S$ no processo de fusão com a membrana humana são a protease 
transmembranar serina 2 (TMPRSS2) e a protease do tipo tripsina das vias aéreas humanas (HAT). A TMPRSS2 é expressa amplamente no trato respiratório humano, em que as células epiteliais também são direcionadas para infecção viral. Um estudo demonstrou que o SARS-CoV-2 usa, principalmente, a TMPRSS2 para a fusão viral (13). Portanto, a TMPRSS2 desempenha um papel importante na promoção da infecção por SARS-CoV-2 nas vias aéreas humanas, e um inibidor da TMPRSS2 pode constituir uma opção para bloquear a entrada do SARS-CoV-2 na célula humana ${ }^{31}$.

Notavelmente, os IFPs do SARS-CoV-2 e SARS-CoV são idênticos. Embora o mecanismo molecular envolvido na entrada do vírus na célula ainda não esteja totalmente esclarecida, é provável que ambos, FP e IFP, participem do processo de entrada viral e, portanto, a proteína $S$, provavelmente, deve ser clivada nos locais de S1/S2 e S2' para a entrada viral. O local de clivagem S2' é idêntico entre o SARS-CoV-2 e o SARS-CoV, enquanto o local de clivagem S1/S2 exibe diferença entre os coronavírus (figura 2). Portanto, o processo de clivagem é assegurado por diferentes proteases das células hospedeiras, dependendo da sequência do local de clivagem $\mathrm{S} 1 / \mathrm{S} 2^{22}$.

Os eventos primários são essenciais para a entrada do vírus, a eficácia e extensão dessa etapa de ativação pelas proteases das células alvo devem regular o tropismo celular e a patogênese viral. No SARS-CoV-2, o sítio 2 de clivagem da região S1/S2 da proteína $\mathrm{S}$ ainda pode ser clivado, possivelmente após a clivagem do local 1.Surpreendentemente, a sequência da proteína $S$ do SARS-CoV-2 contém 4 aminoácidos adicionais antes do local 1 de clivagem da região $\mathrm{S} 1 / \mathrm{S} 2$, formando um local de clivagem pela furina que deve ser clivado para a preparação da proteína S. Isso pode ter fornecido um ganho de função do SARS-CoV-2 para uma mais eficiente transmissão na população humana em comparação com outros betacoronavírus. Assim, apesar de uma alta similaridade com a sequência do genoma de SARSCoV, o SARS-CoV-2 apresenta um local de clivagem pela furina na proteína $S$, ausente nos outros CoVs semelhantes a SARS(22) (figura 2). Isso permite uma clivagem eficaz pela furina e outras proteases e tem um papel no aumento da patogenicidade e da reprodução do SARS-CoV-2 $2^{19,33}$.

A prolina na junção entre S1 e S2 permite a adição de ligações O-glicosídicas que flanqueiam o local de clivagem e são exclusivos do SARS-CoV-2. A grande variação genética na proteína $S$ torna possível que sejam descobertos outros receptores para o SARS-CoV-2, e que ele ainda seja descoberto em outras espécies hospedeiras ${ }^{19,20,34}$. As ligações O-glicosídicas podem criar um "Domínio semelhante à mucina" que protege epítopos ou resíduos-chave na proteína $S$ do SARS-CoV-2. Vários vírus utilizam esse domínio como escudos de glicano para imunoevasão ${ }^{35}$. No entanto, estudos experimentais são necessários para determinar se esses o-glicanos são usados em SARS-CoV-2. Somente o SARS-CoV-2 contém um potencial local de clivagem para proteases de furina. Essa diferença indica que o SARS-CoV-2 humano ganhou um mecanismo distinto para promover sua entrada nas células hospedeiras. Experimentos com SARS-CoV mostraram que a inserção experimental de um local de clivagem pela furina na junção S1-S2 melhorou a fusão célula-célula sem afetar a entrada viral, ou seja, a clivagem crítica na junção S1-S2 pode ocorrer sem ser observada a entrada do vírus na célula. Isso foi demonstrado em um estudo que observou que a entrada do SARS-CoV foi bloqueada por um inibidor específico da catepsina $L$ (protease humana) mesmo tendo ocorrido uma clivagem na junção S1-S2 eficiente ${ }^{21}$.

\section{Origem do SARS-CoV-2}

Com tantos relatos de casos de COVID-19 ligados ao Mercado Huanan em Wuhan, levantou-se a suspeita de que uma fonte animal estava presente nessa localização. Foram sequenciadas 10 amostras de SARS-CoV-2 coletadas no local de origem, sendo observados 99,98\% de identidade genética entre as amostras, sugerindo um novo tipo de beta-CoV. Foi constatado que o SARS-CoV-2 compartilha $79,5 \%$ de sua sequência genética com o SARS-CoV e tem 96,2\% de homologia com um CoV de morcegos. Devido à semelhança de SARSCoV-2 com SARS-CoV de morcegos, sugeriu-se que os morcegos foram os hospedeiros originais. Embora o genoma de RaTG13, cepa de SARS-CoV vinda de um Rhinolophus affinis, seja 96\% idêntica ao genoma do SARS-CoV-2, sua proteína S diverge no RBD, o que sugere que ele não pode-se ligar, eficientemente, a ACE2 humanos ${ }^{23}$, sugerindo a presença de um hospedeiro ainda não relatado.

Acredita-se que os morcegos foram os reservatórios primários para o ebola, assim como com o Sars-Cov, que surgiu na Ásia, em 2003 após ser transmitido de morcegos para civetas e depois para humanos, e com o Mers-Cov, que infectou cerca de 2.500 pessoas desde 2012, após ser transmitido de camelos para humanos ${ }^{1,36-38}$.

O morcego é o segundo mamífero mais comum depois dos roedores, representando quase $20 \%$ de todas as espécies de mamíferos. Existem mais de 1.300 espécies de morcegos, e alguns deles podem viver até 40 anos. É o único mamífero com capacidade de voar, o que aumenta a disseminação da sua população, e seu peculiar sistema imunológico faz que ele seja capaz de abrigar vários vírus. Isso ocorre devido à capacidade do morcego de limitar a inflamação. Os morcegos não reagem à infecção com a resposta inflamatória típica que, muitas vezes, leva a danos patológicos. A inflamação que é mediada, principalemnte pela proteína NLRP3, é significativamente reduzida em morcegos em comparação com camundongos e humanos. Isso ocorre devido ao fato de os morcegos apresentarem adaptações específicas, como a redução do 'priming transcricional', uma etapa fundamental no processo de produção de NLRP3, e como pela presença de variantes únicas do NLRP3 que tornam as proteínas menos ativas neles do que em outras espécies. Assim, em vez de ter uma melhor capacidade de combater infecções, os morcegos têm uma tolerância muito maior. O amortecimento da resposta inflamatória permite que eles sobrevivam e sejam excelentes reservatórios virais $(39,40)$. No entanto, ainda não foi elucidado por meio de qual hospedeiro intermediário o vírus atravessou a barreira das espécies, 
infectou humanos e qual sua rota de transmissão. Ji, et al. (2020) propuseram cobras como portadoras do vírus de morcegos para seres humanos que envolviam recombinação homóloga dentro da proteína S (34). Em um segundo estudo, pesquisadores de Guangzhou, China, sugeriram os pangolins, frequentemente usados na medicina chinesa, como hospedeiros intermediários em potencial do SARS-CoV-2 com base em $99 \%$ de homologia genética entre um CoV descoberto em pangolins e o SARSCoV-2(41). No entanto, $1 \%$ de diferença entre dois genomas é uma grande diferença; assim, são aguardados resultados conclusivos para evidências concretas.

Outro estudo com Pangolins malaios (Manis javanica), ilegalmente importado para a província de Guangdong, constataram um coronavírus (pangolim-CoV) com o genoma 91.02\% e 90.55\% idêntico ao do SARSCoV-2 e do RaTG13, respectivamente. $\mathrm{O}$ Pangolin-CoV é o ancestral mais comum compartilhado entre o SARS-CoV-2 e o RaTG13. E, embora o genoma do RaTG13 tenha maior similaridade com o do SARS-CoV-2, a proteína S1 do Pangolin-CoV é muito mais intimamente relacionada à do SARSCoV-2 do que a do RaTG13. Cinco principais resíduos de aminoácidos envolvidos na interação com ACE2 humano são completamente iguais entre o Pangolin-CoV e o SARSCoV-2, enquanto, no RaTG13, ocorreram quatro mutações de aminoácidos. Isso indica que o SARSCoV-2 possui potencial patogênico semelhante ao Pangolin-CoV, e que a proteína S do SARS-CoV-2, otimizada para a ligação à ACE2 humana, foi resultado de uma seleção natural ${ }^{23,42}$. Assim, os pangolins podem ser o elo mais provável entre o Sars-Cov-2, os morcegos e humanos.

Nem os betacoronavírus de morcegos nem os betacoronavírus de pangolim analisados têm locais de clivagem polibásica $(23,42)$. Apesar de nenhum CoVs animal identificado ter suficiente semelhança para ser progenitor direto do SARS-CoV-2, deve-se levar em consideração que a diversidade dos CoVs em morcegos e outras espécies ainda são pouco estudadas.

Mutações, inserções e deleções podem ocorrer próximo à junção S1-S2 dos CoVs, o que mostra que o local de clivagem polibásica pode surgir por um processo evolutivo natural (43). Para que um vírus precursor adquira o local de clivagem polibásico e mutações na proteína $S$ adequadas para a ligação à ACE2 humana, um hospedeiro animal, provavelmente, teria que ter uma alta densidade populacional, para permitir que a seleção natural seja eficiente, e um gene que codifica ACE2 semelhante ao ortólogo humano ${ }^{43}$.

Todos os genomas de SARS-CoV-2 sequenciados até o momento, apresentam os recursos genômicos esquematizados na figura 2 e são, portanto, derivados de um ancestral que os possuía. Devido à presençaem pangolins de um RBD muito semelhante ao SARS-CoV-2, podemos inferir que essas adaptações também ocorreram no vírus que foi transmitido para os seres humanos. Uma vez adquiridas, essas adaptações permitiram o início da pandemia, surgindo vários casos de modo a serem detectados pelo sistema de vigilância ${ }^{14,23,42}$. A inserção do local de clivagem polibásica pode também ter ocorrido durante a transmissão de humano para humano, resultado de uma seleção natural no hospedeiro humano após a transferência zoonótica².

Estimativas de tempo para a existência do ancestral comum mais recente da SARS-CoV-2 feita com os dados das sequências genômicas apontam para o surgimento do vírus no final de novembro de 2019 a início de dezembro de 20197,24,33,41,43. Portanto, esse cenário pressupõe um período de transmissão humana não reconhecida entre o evento zoonótico inicial e a aquisição do local de clivagem polibásica. Oportunidade suficiente pode ter surgido com a existência de muitos eventos zoonóticos anteriores por um longo período. Isso foi observado para o MERS-CoV, no qual todos os casos humanos foram resultantes de repetidos saltos do vírus de camelos dromedários, produzindo infecções únicas ou cadeias curtas de transmissão, sem adaptações para uma transmissão sustentada ${ }^{38}$. Estudos sorológicos poderiam ser realizados para determinar a extensão da exposição humana prévia ao SARS-CoV-2.

Pesquisas básicas envolvendo passagem de SARS-CoV de morcego em cultura celular e/ou animalmodelos está em andamento no mundo há muitos anos em laboratórios de nível 2 de biossegurança ${ }^{44}$, e existem casos documentados de liberação inesperadade SARS-CoV do laboratório ${ }^{14,45}$. Em teoria, é possível que o SARS-CoV-2 tenha adquirido mutações no RBD por manipulação genética ou durante a adaptação nas passagens em meios de cultura celular, como tem sido observado em estudos de SARS-CoV ${ }^{37,46}$. No entanto, os dados genéticos evidenciam que o SARSCoV-2 não é derivado de nenhuma plataforma de vírus conhecida ${ }^{7,24,41}$.

Além disso, a descoberta de SARS-CoV em pangolins com RBDs quase idênticos ao do SARS-CoV-2, fornece uma hipótese muito mais forte e parcimoniosa de como o SARS-CoV-2 adquiriu essa via de recombinação ou mutação ${ }^{43}$.A aquisição de ambos, local polibásico de clivagem e ligações O-glicosídicas, também vai contra a origem em meio de cultura. Novos locais polibásicos de clivagem foram observados apenas depois de prolongada passagem do vírus da gripe aviária de baixa patogenicidade in vitro ou in vivo ${ }^{47}$. Além disso, uma geração hipotética de SARS-CoV-2 por cultura celular ou passagem em modelos animais exigiria isolamento prévio de um vírus progenitor com similaridade genética muito alta, e a subsequente geração de um local polibásico de clivagem exigiria a passagem repetida em meio de cultura celular e ou modelo animal com receptores ACE2 semelhantes aos humanos. Em ambos os casos, até o momento, não foram descritos estudos. Finalmente, a geração de ligações O-glicosídicas é improvável ter ocorrido devido à passagem em cultura celular, tais características necessitam do envolvimento de um sistema imunológico ${ }^{35}$.

\section{CONSIDERAÇÕES FINAIS}

A disponibilidade das sequências genômicas de RaTG13 ajudou a revelar as principais mutações RBD e o local de clivagem polibásica. As características genômicas descritas aqui podem 
explicar em parte a infectividade e transmissibilidade da SARSCoV-2 em humanos.

Devido aos notáveis recursos de SARS-CoV-2, incluindo o local otimizado de RBD e de clivagem polibásica, é pouco provável um cenário laboratorial para a origem do SARS-CoV-2.

A análise filogenética de uma amostragem significativa de vírus provenientes de diferentes hospedeiros ajudará a esclarecer a origem de SARS-CoV-2.

Mais dados científicos futuros podem adicionar evidências para favorecer uma hipótese em detrimento de outra. Se for observado, futuramente, um local polibásico de clivagem intermediário ou totalmente formado em um vírus do tipo SARS-
CoV-2 de animais, as hipóteses de seleção natural teriam mais suporte. Se o SARS-CoV-2 foi pré-adaptado em outras espécies animais, provavelmente serão observados futuros eventos de reemergência da COVID-19. Se o processo adaptativo ocorreu em seres humanos, mesmo que ocorram transferências zoonóticas repetidas, é improvável que decolem sem a mesma série de mutações.

Para o presente, é de extrema importância obter mais dados genéticos e funcionais sobre o SARS-CoV-2, incluindo estudos em animais, sequenciamento do vírus em casos muito precoces e identificação dos parentes virais mais próximos do SARSCoV-2 circulando em animais.

\section{REFERÊNCIAS}

1. De Wit E, Van Doremalen N, Falzarano D, Munster VJ. SARS and MERS: Recent insights into emerging coronaviruses. Nat Rev Microbiol. 2016;14(8):523-34.

2. Andersen KG, Rambaut A, Lipkin WI, Holmes EC, Garry RF. The proximal origin of SARS-CoV-2. Nat Med. 2020;89(1):44-8.

3. Zhu N, Zhang D, Wang W, Li X, Yang B, Song J, et al. A novel coronavirus from patients with pneumonia in China, 2019. N Engl J Med. 2020;382(8):727-33.

4. Velavan TP, Meyer CG. The COVID-19 epidemic. Trop Med Int Heal. 2020;25(3):278-80.

5. Yi Y, Lagniton PNP, Ye S, Li E, Xu R-H. COVID-19: what has been learned and to be learned about the novel coronavirus disease. Int J Biol Sci. 2020;16(10):175366.

6. Wang C, Horby PW, Hayden FG, Gao GF. A novel coronavirus outbreak of global health concern. Lancet. 2020;395(10223):470-3.

7. Chen Y, Liu Q, Guo D. Emerging coronaviruses: Genome structure, replication, and pathogenesis. J Med Virol. 2020;92(4):418-23.

8. Guan W-J, Ni Z-Y, Hu Y, Liang W-H, Ou C-Q, He J-X, et al. Clinical Characteristics of Coronavirus Disease 2019 in China. N Engl J Med. 2020;1-13.

9. Ren L-L, Wang Y-M, Wu Z-Q, Xiang Z-C, Guo L, Xu T, et al. Identification of a novel coronavirus causing severe pneumonia in human. Chin Med J. 2020;1(2):1-8

10. World Health Organization. Coronavirus disease 2019 (COVID-19) Situation Report - 97. Acesso em 27 de abril: https://www.who.int/docs/ default-source/coronaviruse/situation-reports/20200426-sitrep-97-covid-19. pdf?sfvrsn=d1c3e800_6.

11. Tyrrell, D. A. J. and MLB. Cultivation of viruses from a high proportion of patients with colds. Lancet. 1966;76-7.

12. Raj VS, Mou H, Smits SL, Dekkers DHW, Müller MA, Dijkman R, et al. Dipeptidyl peptidase 4 is a functional receptor for the emerging human coronavirus-EMC. Nature. 2013;495(7440):251-4.

13. Hoffmann M, Kleine-Weber $H$, Schroeder S, Krüger N, Herrler T, Erichsen S, et al. SARS-CoV-2 Cell Entry Depends on ACE2 and TMPRSS2 and Is Blocked by a Clinically Proven Protease Inhibitor. Cell. 2020;1-10.

14. Zhou, P., Yang, X. L., Wang, X. G., Hu, B., Zhang, L., Zhang, W., ... \& Chen HD. Discovery of a novel coronavirus associated with the recent pneumonia outbreak in 2 humans and its potential bat origin. J Chem Inf Model. 2013;53(9):1689-99.
15. Zisman LS, Keller RS, Weaver B, Lin Q, Speth R, Bristow MR, et al. Increased angiotensin-(1-7)-forming activity in failing human heart ventricles: Evidence for upregulation of the angiotensin-converting enzyme homologue ACE2. Circulation. 2003;108(14):1707-12.

16. Yan R, Zhang Y, Li Y, Xia L, Zhou Q. Structure of dimeric full-length human ACE2 in complex with BOAT1. bioRxiv. 2020;1(1):1-20.

17. Wang Q, Zhang Y, Wu L, Niu S, Song C, Zhang Z, et al. Structural and functional basis of SARS-CoV-2 entry by using human ACE2. Cell. 2020;1-11.

18. Yan R, Zhang Y, Li Y, Xia L, Guo Y, Zhou Q. Structural basis for the recognition of SARS-CoV-2 by full-length human ACE2. Science. 2020;367(6485):1444-8.

19. Walls AC, Park Y-J, Tortorici MA, Wall A, McGuire AT, Veesler D. Structure, Function, and Antigenicity of the SARS-CoV-2 Spike Glycoprotein. Cell. 2020;181(2): 281-292.

20. Wrapp D, Wang N, Corbett KS, Goldsmith JA, Hsieh CL, Abiona O, et al. CryoEM structure of the 2019-nCoV spike in the prefusion conformation. Science. 2020;367(6483):1260-3.

21. Follis KE, York J, Nunberg JH. Furin cleavage of the SARS coronavirus spike glycoprotein enhances cell-cell fusion but does not affect virion entry. Virology. 2006;350(2):358-69.

22. Coutard B, Valle C, de Lamballerie X, Canard B, Seidah NG, Decroly E. The spike glycoprotein of the new coronavirus 2019-nCoV contains a furin-like cleavage site absent in CoV of the same clade. Antiviral Res. 2020;176(1-5).

23. Wan Y, Shang J, Graham R, Baric RS, Li F. Receptor recognition by novel coronavirus from Wuhan: An analysis based on decade-long structural studies of SARS. J Virol. 2020;94():1-9.

24. Lu R, Zhao X, Li J, Niu P, Yang B, Wu H, et al. Genomic characterisation and epidemiology of 2019 novel coronavirus: implications for virus origins and receptor binding. Lancet. 2020;395(10224):565-74.

25. Letko M, Marzi A, Munster V. Functional assessment of cell entry and receptor usage for SARS-CoV-2 and other lineage B betacoronaviruses. Nat Microbiol. 2020; 5 (4): 562-569.

26. Chen N, Zhou M, Dong X, Qu J, Gong F, Han Y, et al. Epidemiological and clinical characteristics of 99 cases of 2019 novel coronavirus pneumonia in Wuhan, China: a descriptive study. Lancet. 2020;395(10223):507-13.

27. Wenzhong liu, Hualan L. COVID-19 Disease: ORF8 and Surface Glycoprotein Inhibit Heme Metabolism by Binding to Porphyrin. ChemRxiv. 2020;1:1-23. 
28. Lippi G, Plebani M. Laboratory abnormalities in patients with COVID-2019 infection. Clin Chem Lab Med. 2020;1(1):1-4.

29. Liu W, Li H. COVID-19: Attacks the 1-Beta Chain of Hemoglobin and Captures the Porphyrin to Inhibit Human Heme Metabolism. 2020;1(1):1-7.

30. Xia S, Xu W, Wang Q, Wang C, Hua C, Li W, et al. Peptide-based membrane fusion inhibitors targeting HCOV-229E spike protein HR1 and HR2 domains. Int J Mol Sci. 2018;19(2):8-11.

31. Xia S, Liu M, Wang C, Xu W, Lan Q, Feng S, et al. Inhibition of SARS-CoV-2 (previously 2019-nCoV) infection by a highly potent pan-coronavirus fusion inhibitor targeting its spike protein that harbors a high capacity to mediate membrane fusion. Cell Res. 2020;2(1):1-13.

32. Xia S, Zhu Y, Liu M, Lan Q, Xu W, Wu Y, et al. Fusion mechanism of 2019-nCoV and fusion inhibitors targeting HR1 domain in spike protein. Cell Mol Immunol. 2020;1(1):3-5.

33. Nao N, Yamagishi J MH, Igarashi M, Manzoor R, Ohnuma A TY, Furuyama W, Shigeno A, Kajihara M KN, Yoshida R TA. Genetic Predisposition To Acquire a Polybasic Cleavage Site for Highly. MBio. 2017;8(1):1-15.

34. Ji, W., Wang, W., Zhao, X. F., Zai, J. J., \& Li XG. Homologous recombination within the spike glycoprotein of the newly identified coronavirus 2019-nCoV may boost cross-species transmission from snake to human. J Med Virol. 2020;22(1)1-8.

35. Bagdonaite I, Wandall HH. Global aspects of viral glycosylation. Glycobiology. 2018;28(7):443-67

36. Holmes EC, Dudas G, Rambaut A, Andersen KG. The evolution of Ebola virus: Insights from the 2013-2016 epidemic. Nature. 2016;538(7624):193-200.

37. Sheahan T, Rockx B, Donaldson E, Sims A, Pickles R, Corti D, et al. Mechanisms of Zoonotic Severe Acute Respiratory Syndrome Coronavirus Host Range Expansion in Human Airway Epithelium. J Virol. 2008;82(5):2274-85.
38. Dudas G, Carvalho LM, Rambaut A, Bedford T. MERS-CoV spillover at the camel-human interface. Elife. 2018;791):1-35

39. Lau SKP, Wong ACP, Zhang L, Luk HKH, Kwok JSL, Ahmed SS, et al. Novel bat alphacoronaviruses in Southern China support chinese horseshoe bats as an important reservoir for potential novel coronaviruses. Viruses. 2019;11(5):1-19.

40. Ahn M, Anderson DE, Zhang Q, Tan CW, Lim BL, Luko K, et al. Dampened NLRP3-mediated inflammation in bats and implications for a special viral reservoir host. Nat Microbiol. 2019;4(5):789-99.

41. Xiao K, Zhai J, Feng Y, Zhou N, Zhang X, Zou J-J, et al. Isolation and Characterization of 2019-nCoV-like Coronavirus from Malayan Pangolins. bioRxiv. 2020;1(1)1-31.

42. Zhang T, Wu Q, Zhang Z. Pangolin homology associated with 2019-nCoV. bioRxiv. 2020;1(2):1-23.

43. Cui J, Li F, Shi ZL. Origin and evolution of pathogenic coronaviruses. Nat Rev Microbiol. 2019;17(3):181-92.

44. Ge XY, Li JL, Yang X Lou, Chmura AA, Zhu G, Epstein JH, et al. Isolation and characterization of a bat SARS-like coronavirus that uses the ACE2 receptor. Nature. 2013;503(7477):535-8.

45. Chan KP, Wong CW, Ph D, Ng LC, Ph D, Stanton LW, et al. Laboratory-Acquired Severe Acute Respiratory Syndrome. 2004;1740-5.

46. Liu P, Chen W, Chen JP. Viral metagenomics revealed sendai virus and coronavirus infection of malayan pangolins (manis javanica). Viruses. 2019;11(11).

47. Ito $T$, Goto $H$, Yamamoto $E$, Tanaka H, Takeuchi $M$, Kuwayama M, et al. Generation of a Highly Pathogenic Avian Influenza A Virus from an Avirulent Field Isolate by Passaging in Chickens. J Virol. 2001;75(9):4439-43. 